\title{
Prevalence of Transfusion Transmissible Infections (HBV, HCV, HIV and Treponema pallidum in Volunteer Blood Donors in Shirajganj District
}

\author{
Md. Mahmudul Hasan, Tahmina Shammi and Md. Shahidul Kabir ${ }^{*}$ \\ Department of Microbiology, Stamford University Bangladesh
}

\begin{abstract}
Blood and its components are essential for life and often required to be transfused in critical health condition. However, such transfusion is reported to be associated with the risk of transfusion transmissible infections (TTIs) with notable pathogens e.g. Hepatitis B virus (HBV), Hepatitis C virus (HCV), Human immunodeficiency virus (HIV) and Treponema pallidum. These pathogens are of major public health concern especially in developing countries like Bangladesh. Increase in the number of TTIs is found to be associated with improper management of safe blood transfusion protocol (SBTP) and unethical practices. This study focuses on the prevalence of such TTIs in volunteers' blood collected between October and December 2018 from Sakhawath Memorial and Avicina Hospitals in Shirajgong district. Prevalence rate of HIV, HBsAg, HCV and Treponema pallidum were $1.2 \%, 6.8 \%, 0.8 \%$ and $1.6 \%$, respectively. Among the infected individuals, $75 \% \mathrm{HIV}$ positive cases were professionals, $70 \% \mathrm{HCV}$ infected cases wwere from other professional groups and $\mathbf{5 0 \%}$ of syphilis infected were homemakers. Male donors showed higher incidence rate of $\mathrm{HBV}(65 \%), \mathrm{HCV}(72 \%)$ and $\mathrm{HIV}(85 \%)$ compared to the female donors. Although the findings of the study showed prevalence of TTIs in volunteer blood donors (VBDs) at an alarming rate, most of the infected individuals were not aware of their infections and potential risk of transmission from them. It is necessary to create awareness among blood donors about possible causes of transmission and prevention of infection. Such initiative from both governmental and non-governmental organizations can help reduce TTIs among VBDs.
\end{abstract}

Keywords: Blood donor, TTI, pathogenic bacteria

\section{Introduction}

More than 112.5 million units of blood are collected from donors' every year worldwide ${ }^{1}$. If safe blood transfusion is not performed, it can be life-threatening due to the transmission of blood-borne pathogens called transfusion transmissible infections (TTIs). TTIs include human immunodeficiency virus (HIV), hepatitis A, B, C, D, Treponema pallidum, malaria, West Nile virus (WNV), Cytomegalovirus (CMV), Human T-cell lymphotrophic viruses (HTLVs), Parvovirus B19, etc. ${ }^{2}$ According to CDC, TTIs may also result from new or emerging infectious agents e.g. new variant Creutzfeldt-Jacob Disease and recently emerging Chikungunya virus, with potential of transmission from person-to-person ${ }^{2-3}$. Globally, 170 million people are chronically infected with HCV, 350 million people with HBV and 38 million people are infected with HIV ${ }^{4}$. To assure the quality and safety, World Health Organization (WHO) recommends screening of at least major TTIs in donated blood ${ }^{5}$. It is estimated that 0.6 million units of blood are required annually in Bangladesh. All donated units of blood in the country must be screened for HIV, Hepatitis B and C, syphilis and malaria as per the Safe Blood Act 2002 and Safe Blood Transfusion Program (SBTP) ${ }^{6}$. In 2010, the prevalence of TTI markers was found to be $<1 \%{ }^{6}$. However, the number of HIV and other TTIs is increasing in Bangladesh. To realize the true picture of TTIs in Bangladesh small rural districts should also be studied in addition to large city corporations e.g. Dhaka,
Chittagong, etc. In the present study, prevalence of HIV, HBV, $\mathrm{HCV}$ and Treponema pallidum was investigated among volunteer blood donors in Shirajganj district, Bangladesh.

\section{Materials and Methods}

\section{Study design}

The study was conducted in two laboratories of Sakhawat H. Memorial Hospital and Avicena Hospital in Shirajgang districts. The study was carried out over a period of three months, between October and December, 2018. A total of 250 samples were studied during this sampling period. HBsAg, anti-HIV, anti-HCV and VDRL tests were conducted on the collected blood. Rapid test kits were used for all screening. Prevalence rates were calculated for the Transfusion-Transmissible Infections per hundred donations.

\section{Sample Preparation}

Blood samples $(5 \mathrm{cc})$ were collected from donated blood bags and transported in sterile test tubes and allowed to stand at room temperature for 10 minutes. Then the blood was centrifuged at 2000 revolution per minute for 5 minutes. Serums were collected in Eppendorf tubes and stored at $-20^{\circ} \mathrm{C}$ until use.

\section{Detection of Antigen/Antibody}

Anti-HIV, HBV Surface Antigen (HBsAg), anti-HCV and antiTP (Syphilis) was screened by Rapid Test kits. Information of test kits are given below- 


\section{Epidemiological Study}

Along with antigen detection a survey was conducted with questionnaire filled by the VBDs for thorough investigation of TTIs in different gender, age groups, and professional groups and to understand the underlying reasons of these infections.

\section{Statistical analysis}

All positive samples were repeated 3 times before labeling as seropositive and respective blood units were discarded. All data were analyzed by Microsoft-EXCEL $2016^{7}$.

\section{Results and Discussion}

This study was conducted for three months between October 2018 and December 2018 to determine the prevalence of TTIs in blood donated by volunteer blood donors. A total of 200 samples from Sakhawath Memorial Hospital and 50 samples from Avicina Hospital Ltd., Shirajganj were included in this study. Comparative results for both the donors from these hospitals are shown in Table 4.1. The proportions of HIV, HBV, HCV and syphilis positive samples were not significantly different between the two hospitals $(\mathrm{p}<0.01)$.

Table 2 shows the incidence of infections due to HBV, HCV, HIV and Treponema pallidum in both male and female donors. Numbers of male and female donors were 198 and 52, respectively. There was no significant difference of such infections in male and female donors $(\mathrm{p}<0.01)$. In our study, most prevalent
TTIs was found to be HBV, 6.8\%; Syphilis, 1.6\%; HIV, 1.2\% and $\mathrm{HCV}, 0.8 \%$.

Results of blood screening tests were further analyzed for different professionals e.g. students, service holders, business personnel, home makers and others. Table 3 shows that $75 \%$ of service holder were found to be infected with HIV; $70 \%$ were infected with $\mathrm{HCV}$ other professional groups and $50 \%$ of syphilis patients were home makers.

Occurrence of infections with HBV, HCV, HIV and Treponema pallidum in different age groups of volunteer blood donors is shown in Table 4. It was found that young and middle aged donors of 18-35 years were mostly affected by the mentioned pathogens.

Frequency of infections of HBV, HCV, HIV and Treponema pallidum in male and female donors is shown in Table 5. There was no significant difference between the male and female groups of blood donors $(\mathrm{p}<0.01)$.

Table 6 shows data was analyzed for possible reasons of such infections such as, HBV, HCV, HIV and Treponema pallidum. Pre-donation survey questionnaires was used for collecting data on previous history such as, unprotected sex, parental history, intravenous drug reception fusion of blood or blood components and other than these are considered unknown causes. It was found that most of the infected donors showed positive result due to unknown reasons (61.0-90.0\%). The second highest cause was sex relation as per the information provided in the survey form.

Table 1. Details of the kits used in this study

\begin{tabular}{lll}
\hline Kit Used & Marker & Other Information \\
\hline ABON, USA & Anti-HIV & Sensitivity: $100 \%$ \\
& & Specificity $99.7 \%$ \\
ABON, USA & Relative Sensitivity $>99 \%$ \\
& Relative Specificity $96.7 \%$ \\
& Accuracy $98.3 \%$ \\
ABON, USA & Relative Sensitivity $>99.5 \%$ Relative Specificity $99.78 \%$ \\
& Anti-HCV & Accuracy $99.85 \%$ \\
ABON, USA & Relative Sensitivity $99.5 \%$ \\
& Anti-TP & Relative Specificity $99.8 \%$ \\
& & Accuracy $99.7 \%$ \\
\hline
\end{tabular}

Table 2: Proportions of HIV, HBV, HCV and syphilis positive samples in donated blood samples in two hospitals in Shirajganj district

\begin{tabular}{lccccc}
\hline Study sites & $\begin{array}{c}\text { Samples } \\
\text { screened }\end{array}$ & $\begin{array}{c}\text { HIV } \\
\text { positive }\end{array}$ & $\begin{array}{c}\text { HBV } \\
\text { positive }\end{array}$ & $\begin{array}{c}\text { HCV } \\
\text { positive }\end{array}$ & $\begin{array}{c}\text { Syphilis } \\
\text { positive }\end{array}$ \\
\hline Sakhawath Memorial Hospital Shirajganj & 200 & $2(1.0 \%)$ & $12(6.0 \%)$ & $1(0.5 \%)$ & $2(1.0 \%)$ \\
Avicina Hospital Ltd. Shirajganj & 50 & $1(0.4 \%)$ & $5(10.0 \%)$ & $1(0.4 \%)$ & $2(0.8 \%)$ \\
\hline Total & 250 & $3(1.2 \%)$ & $17(6.8 \%)$ & $2(0.8 \%)$ & $4(1.6 \%)$ \\
\hline
\end{tabular}


Prevalence of Transfusion Transmissible Infections (HBV, HCV, HIV

Table 3: Results of blood screening test for male and female donors

\begin{tabular}{llcccccc}
\hline Screening Status & \multicolumn{2}{c}{ Male $(n=198)$} & \multicolumn{2}{c}{ Female $(n=52)$} & \multicolumn{2}{c}{$\begin{array}{c}\text { Total patients screened } \\
(n=250)\end{array}$} \\
\hline \multirow{2}{*}{ HIV } & Reactive & 3 & $1.5 \%$ & 0 & $0 \%$ & 3 & $1.2 \%$ \\
\multirow{3}{*}{$\mathrm{HBV}$} & Non-reactive & 195 & $98.4 \%$ & 52 & $100 \%$ & 245 & $98.0 \%$ \\
& Reactive & 15 & $7.5 \%$ & 2 & $3.8 \%$ & 17 & $6.8 \%$ \\
$\mathrm{HCV}$ & Non-reactive & 183 & $73.2 \%$ & 50 & $96.1 \%$ & 233 & $93.2 \%$ \\
& Reactive & 2 & $0.8 \%$ & 0 & $0 \%$ & 2 & $0.8 \%$ \\
\multirow{3}{*}{ Syphilis } & Non-reactive & 196 & $78.4 \%$ & 52 & $100 \%$ & 248 & $99.2 \%$ \\
& Reactive & 1 & $0.4 \%$ & 3 & $5.2 \%$ & 4 & $1.6 \%$ \\
& Non-reactive & 195 & $78.0 \%$ & 49 & $94.2 \%$ & 246 & $98.4 \%$ \\
\hline
\end{tabular}

Table 4. Incidence of HBV, HCV, HIV and Treponema pallidum infections among volunteer blood donors from different professional groups

\begin{tabular}{lcccc}
\hline Study population & HBsAg $(\%)$ & HCV $(\%)$ & HIV $(\%)$ & Syphilis $(\%)$ \\
\hline Students & $25 \%$ & $0 \%$ & $0 \%$ & $0 \%$ \\
Service holders & $30 \%$ & $30 \%$ & $75 \%$ & $45 \%$ \\
Business personnel & $05 \%$ & $0 \%$ & $0 \%$ & $0 \%$ \\
Home makers & $10 \%$ & $0 \%$ & $0 \%$ & $50 \%$ \\
Others & $30 \%$ & $70 \%$ & $25 \%$ & $5 \%$ \\
\hline
\end{tabular}

Table 5. Incidence of $H B V, H C V, H I V$ and Treponema pallidum infections in different age groups of blood donors

\begin{tabular}{lcccc}
\hline Study population & HBsAg $(\%)$ & HCV $(\%)$ & HIV $(\%)$ & Syphilis $(\%)$ \\
\hline $18-25$ years & 09 & 00 & 02 & 01 \\
26-35 years & 05 & 01 & 01 & 02 \\
$36-50$ years & 03 & 01 & 00 & 01 \\
\hline
\end{tabular}

Table 6: Incidence of HBV, HCV, HIV and Treponema pallidum in male and female blood donors

\begin{tabular}{lcccc}
\hline Study population & HBV $(\%)$ & HCV $(\%)$ & HIV $(\%)$ & Syphilis (\%) \\
\hline Male & 65.0 & 72.0 & 85.0 & 45.0 \\
Female & 35.0 & 28.0 & 15.0 & 55.0 \\
\hline
\end{tabular}

Table 7: Possible causes of infections due to HBV, HCV, HIV and Treponema pallidum in volunteer blood donors

\begin{tabular}{lcccc}
\hline Study population & HBsAg (\%) & HCV (\%) & HIV (\%) & Syphilis (\%) \\
\hline Unknown cause & $61 \%$ & $90 \%$ & $80 \%$ & $85 \%$ \\
Unprotected Sex & $12 \%$ & $00 \%$ & $15 \%$ & $10 \%$ \\
Parental history & $02 \%$ & $00 \%$ & $05 \%$ & $00 \%$ \\
Intravenous Drug reception & $00 \%$ & $00 \%$ & $00 \%$ & $00 \%$ \\
Transfusion of blood or blood & $25 \%$ & $10 \%$ & $00 \%$ & $00 \%$ \\
components & & & & \\
\hline
\end{tabular}

\section{Discussion}

Blood transfusion is a potential route for the transmission of HIV, HBV, HCV and Treponema pallidum, which are commonly known as Transfusion Transmissible Infections (TTIs) ${ }^{8,9}$. Considering the high morbidity and mortality rate of these TTIs a number of studies have been going on to determine the prevalence, risk factors and prevention mechanism of such infections. In Bangladesh Prevalence of HIV, HBV, HCV and Syphilis infection has been investigated in selected regions, like Chittagong ${ }^{10}$, Khulna ${ }^{7}$, Dhaka ${ }^{11}$ etc. and in groups professional blood donors ${ }^{12-13}$, pregnant mothers ${ }^{14}$, children ${ }^{15}$, patients with acute hepatitis ${ }^{16}$, prostitutes $^{17}$, female sex workers ${ }^{18}$, drug users ${ }^{19}$ etc. However, volunteer blood donors from rural settings are underrepresented in these studies. In this study, we focused on 
the prevalence of TTIs (HIV, HBV, HCV and Treponema pallidum infection) in non-professional blood donors from an under represented district, Shirajganj.

World Health Organization (WHO) has ranked HIV/AIDS as the $6^{\text {th }}$ deadliest disease for human, as it caused almost 1.78 million deaths resulting in $3.1 \%$ of total human death. In Bangladesh current prevalence rate of HIV is $<0.01 \%$ but this trend is going upwards ${ }^{20}$. Since the detection of the first HIVpositive person in 1989, the current HIV-statistics stands with around 13,000 people living with HIV of which 4,400 are women, only 2470 infected patients are on antiretroviral therapy, and 1100 $\operatorname{died}^{20-21}$.

Prevalence rate of HIV positive individual is less than $0.01 \%$ which categorizes Bangladesh to be a low HIV-prevalence country. Even in the high risk or key population (sex worker, intravenous drug user, worker returning from foreign countries), the percentage is near $1 \%^{22}$. In this study prevalence rate of HIV was found $1.2 \%$. In previous studies prevalence of HIV among nonprofessional blood donors was found to be $0 \%$ in both Dhaka ${ }^{19}$ and Chittagong city ${ }^{10}$. But a recent study demonstrated $10 \%$ increase in the number of new HIV infections each year ${ }^{20-}$ 21 , which explains the high prevalence rate in our study. Again, when gender based prevalence was observed, prevalence rate of HIV was higher in male population (1.5\%) within the age group of 18-35 years than in female population $(0 \%)$ and transgender or hijra community (who are also considered righ risk group) ${ }^{23}$ was not included in this study. $75 \%$ of the HIV positive individuals were service holders and $25 \%$ were from other (farmer, unemployed etc.) professional groups. In a number of studies sex workers, drivers of heavy load vehicles and workers returning from foreign countries were found to be highly infected professional groups. In present study, $80 \%$ HIV infected patient were unaware of their infection, $15 \%$ was infected due to unprotected sexual behavior and $5 \%$ had parental history or vertical transmission. HIV infection due to intravenous drug reception, reception of blood or blood related product was not found in our study however, Azim et al., 2008 found, 7\% HIV infection was attributed to intravenous drug users in Dhaka.

Among the TTIs, HBV is found to be most prevalent infection. According to the World Health Organization (WHO) reports, the prevalence of $\mathrm{HBV}$ varies from $0.008 \%$ to $6.08 \%$ in different parts of the world ${ }^{24}$. According to past reports, Prevalence of HBsAg was reported $7.8 \%$ in apparently healthy people in Bangladesh who applied for jobs in foreign countries ${ }^{16}$ and $4.88 \%$ in non-profession blood donors ${ }^{10}$. This study shows the prevalence of HBsAg in $6.8 \%$ in non-professional blood donors of Shirajganj district. Most of the previous studies were specific for donors of a particular region and specific groups hence cannot be considered as the general scenario of HBsAg prevalence in the community of non-professional blood donors. In other studies $10.7 \%$ first time blood donors and 3\% voluntary blood donors were HBsAg positive in Japan ${ }^{25}$ and Sub-Saharan African ${ }^{26}$ respectively. A research conducted on commercial sex workers in Dhaka city, Bangladesh demonstrated that $78.7 \%$ had serologic evidence of current or past HBV infection ${ }^{17}$. In this study the age of volunteer blood donors was $18-50$ years and $79.2 \%$ was male and $20.8 \%$ was female donors. HBsAg positive results were mostly showed by Service holder (30\%), other group (30\%), student $(25 \%)$ and home maker (10\%). Again a significant portion of individual was infected by unknown reasons $(61 \%)$ and transfusion of blood or blood related products (21\%).

According to a report by $\mathrm{WHO}$, the prevalence of $\mathrm{HCV}$ is $0.004 \%$ to $1.96 \%$ in different parts of the world ${ }^{24}$. In our study HCV prevalence was found to be $0.8 \%$. All the infected individuals were male donors, $75 \%$ were service holder and $25 \%$ were from other professions. Whereas, in Chittagong, prevalence of $\mathrm{HCV}$ was $0.92 \%$ and $100 \%$ of positive individual $(5.71 \%$ of blood donors) were businessman and about $50 \%$ positive donors had an intravenous drug reception history ${ }^{10,23}$. Another study reported that $1.2 \%$ professional blood donors were positive for $\mathrm{HCV}^{27}$, anti-HCV was found to be positive in $7.3 \%$ among the blood donors in Gourgia ${ }^{28}, 4.16 \%$ among the blood donors in Pakistan ${ }^{29}$, and $0.285 \%{ }^{30}$ among the replacement blood donors in the Western India ${ }^{10}$.

VDRL test for Trepnema pallidum showed the prevalence of $1.6 \%$ among non professional blood donors of Shirajganj district. Among the infected individuals, aged between 26-50 years 75\% were female and $25 \%$ were male donors. According to one report, incidence of Syphilis was greater among the service holders $(2.74 \%)$ who were within the age group of 26-35 years ${ }^{10}$. The highest prevalence rate of syphilis infection among service holders was unknown but there are possibilities of sexual transfer of such infections.

Prevalence of syphilis was found to be $32.60 \%$ in street based, $57 \%$ were in brothel based female sex workers (FSWs) in Dhaka, Bangladesh ${ }^{18}$. This result is comparable with our neighboring country, where FSWs were found $24.2 \%$ and $22.9 \%$ syphilispositive in the Ahmedabad and Surat in India ${ }^{31}$. But the prevalence of syphilis among blood donors in Bangladesh was not well documented. A cross sectional study among the slum dwellers in Dhaka city Bangladesh showed higher incidence of Syphilis, $11.5 \%{ }^{32}$ than the present study (1.6\%).

\section{Conclusion}

The incidence of TTIs in blood donated for transfusion at Shirajganj is high compared to national context. Known that all donors are voluntary, therefore proper screening of donated blood for HIV, HBsAg, HCV and Treponema pallidum with test methods having better diagnostic performance should be employed It is important to screen all blood products before reception and stop professional blood donation according to WHO an SBTA Stringent donor selection, encouragement of blood donation from voluntary donors and creating awareness from both government and non government organizations (NGO) 
should be strengthened. Finally, vaccination for TTIs should be made affordable or free of cost if possible to all blood donors.

\section{References}

1. World Health Organization. 2017. Global Database on Blood Safety Report 2016. World Health Organization, Geneva, Switzerland.

2. British Columbia Centre for Disease Control. 2004. Communicable Disease Control Transfusion Transmissible Infection. British Columbia, Canada.

3. Choudhury N. 2010. Transfusion transmitted infections: How many more? Asian J. Transfusion Sci., 24(2): 71-72. doi: 10.4103/0973-6247.67017

4. Khodabandehloo M, Roshani D and Sayehmiri K. 2013. Prevalence and trend of hepatitis $\mathrm{C}$ virus infection among blood donors in Iran: A systematic review and meta-analysis. J. Res. Med. Sci. 18: 674-82.

5. Negash M, Ayalew M, Geremew D and Workineh M. 2019. Seroprevalence and associated risk factors for HIV, Hepatitis B and C among blood Donors in South Gondar District blood Bank, Northwest Ethiopia. BMC Inf. Dis. 430: 1-10 doi:10.1186/s12879-019-4051-y

6. Islam MB. 2009. Blood transfusion services in Bangladesh. Asian $J$ TransSci. 3(2):108-110.

7. Alom SMT, Mondal KJ, Tarafder S, Sonia FA, Chowdhury PK and Islam MS. 2017. Sero-prevalence of Transfusion Transmissible Infections among Voluntary Blood Donors of Khulna Medical College Hospital. Bangladesh Med. J. 46(2): 16-21.

8. Giri PA, Deshpande JD, Phalke DB and Karle LB. 2012. Seroprevalence of transfusion transmissible infections among voluntary blood donors at a tertiary care teaching hospital in rural area of India. J. Fam. Med. Pri. Care. 1(1): 48-51.

9. Prakash P, Bobati SS and Basavaraj V. 2016. Prevalence of Transfusion Transmissible Infections among Blood Donors in a Tertiary Care Hospital of Mysuru District - A Six Years Study. Int. J. Trop. Dis. \& Health. 16(3): $1-8$.

10. Alam MZ, Hossain MA and Chowdhury MA. 2015. Prevalence and risk factors of Human Immunodeficiency virus, Hepatitis B virus, Hepatitis $\mathrm{C}$ virus and Syphilis infections among nonprofessional blood donors in Chittagong, Bangladesh. Asian J. Med. Biol. Res. 1(3): 518-525; doi: 10.3329/ajmbr.v1i3.26475.

11. Ara F, Alam ABMM, Rahman M, Jahan A, Yusuf MA, Hassan MS, Sonia SF, Nasreen Z and Biswas J. 2014. Prevalence of Transfusion Transmitted Infection among BloodDonors at Medical University in Bangladesh. $J$. Shaheed Suhrawardy Med. Col. 6(1): 11-13.

12. Mustafa M, Islam MN and Rahman MH. 1989a. Prevalence of Hepatitis B surface antigen among professional blood donors at Dhaka. Bangladesh. Med. J. 18:117-22.

13. Mustafa M, Islam MN, Rahman M and Salauddin ARM. 1989b. Prevalence of Hepatitis B surface antigen (HBsAg) among prostitutes of Dhaka. Bangladesh Med. and Hyg. Res. Coun. Bull. 15:67-72.

14. Akhter S, Talukder MQ, Bhuiyan N, Chowdhury TA, Islam MN and Begum S. 1992. Hepatitis B virus infection in pregnant mothers and its transmission to infants. Indian J. Ped. 59: 411-5.

15. Incomplete name Chowdhury. 1997. Studies on the efficacy of Hepatitis $B$ virus vaccine in Bangladesh Children. Thesis, MD (pediatrics), Dhaka Shisu Hospital.
16. Islam MN, Islam KMN and Islam N. 1984. Hepatitis-B virus infection in Dhaka, Bangladesh. Bangladesh Med. Res. Coun. Bull. 10: 1-6.

17. Satter H and Islam MN. 1996. Hepatitis B virus markers among the prostitutes of Dhaka. Bangladesh Med. Res. Coun. Bull. 22: 8-11.

18. Rahman M, Alam A, Nessa K, Hossain A, Nahar S, Datta D, Khan SA, Mian RA, and Albert MJ. 2000. Etiology of sexually transmitted infection among street-based female sex workers in Dhaka Bangladesh. $J$ Clin Microbiol. 38(3): 1244-1246.

19. Shirirn T, Ahmed T, Iqbal A, Islam M and Islam MN. 2000. Prevalence and risk factors of Hepatitis B virus, Hepatitis C virus, and Human immunodificiency virus infection among drug addicts in Bangladesh. $J$. Health Population Nut. 18: 145-50.

20. Sultana T, Bin Manjur OH, Omar M and Kabir Y. 2019. HIV Landscape in Bangladesh and a Comparison to the Global Context. Int. J. HIV/AIDS Res. 6(2):189-195.

21. UNAIDS. UNAIDS Data 2017. 2017:1-248.

22. UNAIDS. UNAIDS Data 2018. 2018:1-376.

23. Azim T, Rahman M, Alam MS, Chowdhury IA, Khan R, Reza M, Rahman M, Chowdhury EL, Hanifuddin M and Rahman ASM. 2008. Bangladesh moves from being a low-prevalence nation for HIV to one with a concentrated epidemic in injecting drug users. Int. J. STD and AIDS. 19: 327-33.

24. Farshadpour FTR, Tajbakhsh S, Gholizadeh Tangestani M, Hajiani G and Sharifi N. Prevalence and trends of transfusion-transmissible viral infections among blood donors in south of Iran: An eleven-year retrospective study. PLoS One. 6: 175-80.

25. Mbanya DN, Takam D and Ndumbe PMS. 2003. Serological findings amongst first-time blood donors in Yaoundé, Cameroon: is safe donation a reality or a myth? Trans. Med. 13: 267-73.

26. Batina A, Kabemba S and Malengela R. 2007. Infectious markers among blood donors in Democratic Republic of Congo (DRC). Revue Médicale de Bruxelles. 28: 145-9.

27. Chowdhury MR. 1999. Modern Medical Microbiology, 5th edition. Bishwa Parichaya, Dhaka.

28. Butsashvili M, Tsertsvadze T, Mcnutt LA, Kamkamidze G, Gvetadze R and Badridze N. 2001. Prevalence of Hepatitis B, Hepatitis C, Syphilis and HIV in Georgian blood donors. Europ. J. Epi. 17: 693-5.

29. Bhatti FA, Ullah Z, Salamat N, Ayub M and Ghani E. 2007. Anti-hepatits $\mathrm{B}$ core antigen testing, viral markers and occult hepatitis B virus infection in Pakistani blood donors. Transfusion, 47: 74-9.

30. Garg S, Mathur DR and Garg DK. 2001. Comparison of seropositivity of HIV, HBV, HCV and syphilis in replacement and voluntary blood donors in western India. Indian J. Path. Microbiol. 44: 409-12.

31. Desai VK, Kosambiya JK, Thakor HG, Umrigar DD, Khandwala BR and Bhuyan KK. 2003. Prevalence of sexually transmitted infections and performance of STI syndromes against astiological diagnosis, in female sex workers of red light area in Surat, India. Sex. Trans. Infect. 79: 111115 .

32. Sabin KM, Rahman M, Hawkes S, Ahsan K, Begum L, Black RE and Baqui AH. 2003. Sexually transmitted infections prevalence rates in slum communities of Dhaka, Bangladesh. Int. J. STD and AIDS. 14:614-21. 